\title{
Successful Medical Management of Interstitial Pregnancy
}

\author{
${ }^{1}$ Krishna Dahiya, ${ }^{2}$ Veenu Kadian, ${ }^{3}$ Shaveta Sangwan
}

\begin{abstract}
Interstitial pregnancies account for 2 to $4 \%$ of all tubal pregnancies and have seven times higher mortality rates than ectopic pregnancy in general. It poses a significant risk of bleeding and rupture. The conventional treatment of Interstitial pregnancy involves resection of the cornual tissue. Conservative management with methotrexate systemically and locally has been reported with varying doses. We present a case of interstitial pregnancy diagnosed at 11 weeks of gestation and with high human chorionic gonadotropin (hCG) levels managed successfully with systemic methotrexate.
\end{abstract}

Keywords: Interstitial, Medical treatment, Methotrexate.

How to cite this article: Dahiya K, Kadian V, Sangwan S. Successful Medical Management of Interstitial Pregnancy. J South Asian Feder Obst Gynae 2015;7(3):240-242.

Source of support: Nil

Conflict of interest: None

Date of received: 22 October 2015

Date of acceptance: 27 November 2015

Date of publication: December 2015

\section{INTRODUCTION}

Interstitial pregnancies account for 1 in 2500 to 5000 live births. It has seven times higher mortality rates than ectopic pregnancies in general. ${ }^{1}$ The average gestational age at presentation is about 7 to 8 weeks. ${ }^{2}$ The patients may be asymptomatic, have abdominal pain, vaginal bleeding or may present with rupture and hemorrhagic shock. ${ }^{3}$ Treatment depends upon the clinical situation. Ruptured interstitial pregnancy requires an immediate surgery and resection of cornual tissue. In asymptomatic patients, methotrexate has been successfully used with proper monitoring. ${ }^{4}$ We present a case of cornual pregnancy managed conservatively.

\section{CASE REPORT}

A woman 26 years of age, G4P0A3 with 11 weeks of amenorrhea was referred to our hospital in view of cornual

\footnotetext{
${ }^{1}$ Professor, ${ }^{2,3}$ Assistant Professor

${ }^{1-3}$ Department of Obstetrics and Gynecology, Pandit Bhagwat Dayal Sharma Post Graduate Institute of Medical Sciences Rohtak, Haryana, India

Corresponding Author: Krishna Dahiya, Professor Department of Obstetrics and Gynecology, 74-R, Model Town Rohtak-124001, Haryana, India, Phone: 01262211888, e-mail: krishnadahiya@rediffmail.com, drkrishnadahiya@gmail.com
}

pregnancy. Patient was asymptomatic and diagnosed as cornual pregnancy on ultrasound. On admission, patient was conscious, oriented, pulse rate was $88 / \mathrm{min}$, blood pressure was 110/70 $\mathrm{mm} \mathrm{Hg}$ and pallor was absent. On per abdomen examination, there was no tenderness and on per vaginum examination, cervix was soft, uterus was 8 weeks in size, no cervical motion tenderness was there and no adnexal mass was palpable bilaterally. Ultrasonography revealed gestational sac with fetal node of crown rump length (CRL) $15 \mathrm{~mm}$ corresponding to gestational age of $8 \pm 1$ weeks seen in left cornual region with no cardiac activity. Human chorionic gonadotropin (hCG) levels were 44122 IU/l. Magnetic resonance imaging (MRI) (Fig. 1) was done which showed gestational sac in left cornu of uterus suggestive of interstitial pregnancy. Leukocyte count and liver function tests (LFTs) were normal. As the patient was nulliparous, with history of recurrent abortions and hemodynamically stable so conservative management was adopted. Patient was given injection methotrexate $1 \mathrm{mg} / \mathrm{Kg}$ body weight intramuscular and injection leucovorin $5 \mathrm{mg}$ intramuscular on alternate days for 4 doses each. Her hCG levels were repeated on day 7 and was $2666.0 \mathrm{IU} / 1$ (94\% fall). No side effects of methotrexate were noted. Patient was discharged and followed weekly with hCG levels till hCG levels were $<6.0$ IU/1. On repeat ultrasonography, after 5 weeks, uterus was normal and no adnexal mass was visualized.

\section{DISCUSSION}

Interstitial pregnancy is gestation that implants in the proximal, intramural portion of the fallopian tube. $^{5}$ Anatomically, the feature that distinguishes the interstitial and angular is the relationship between the pregnancy and either the uterine cavity or, at laparoscopy, the round ligament. Angular pregnancy implants in the angle of the uterine cavity, while the interstitial pregnancy implants just laterally. At laparoscopy, the 'bulge' of angular pregnancy is medial to the round ligament, with interstitials being lateral. But the two terms are often used interchangeably. Risk factors for the development of interstitial pregnancy include previous ectopic pregnancy, previous salpingectomy, uterine anomalies, in vitro fertilization (IVF), ovulation induction and sexually transmitted infection (STI). ${ }^{6,7}$ Our patient had taken ovulation induction drugs for infertility. Patients may be asymptomatic or present with symptoms 


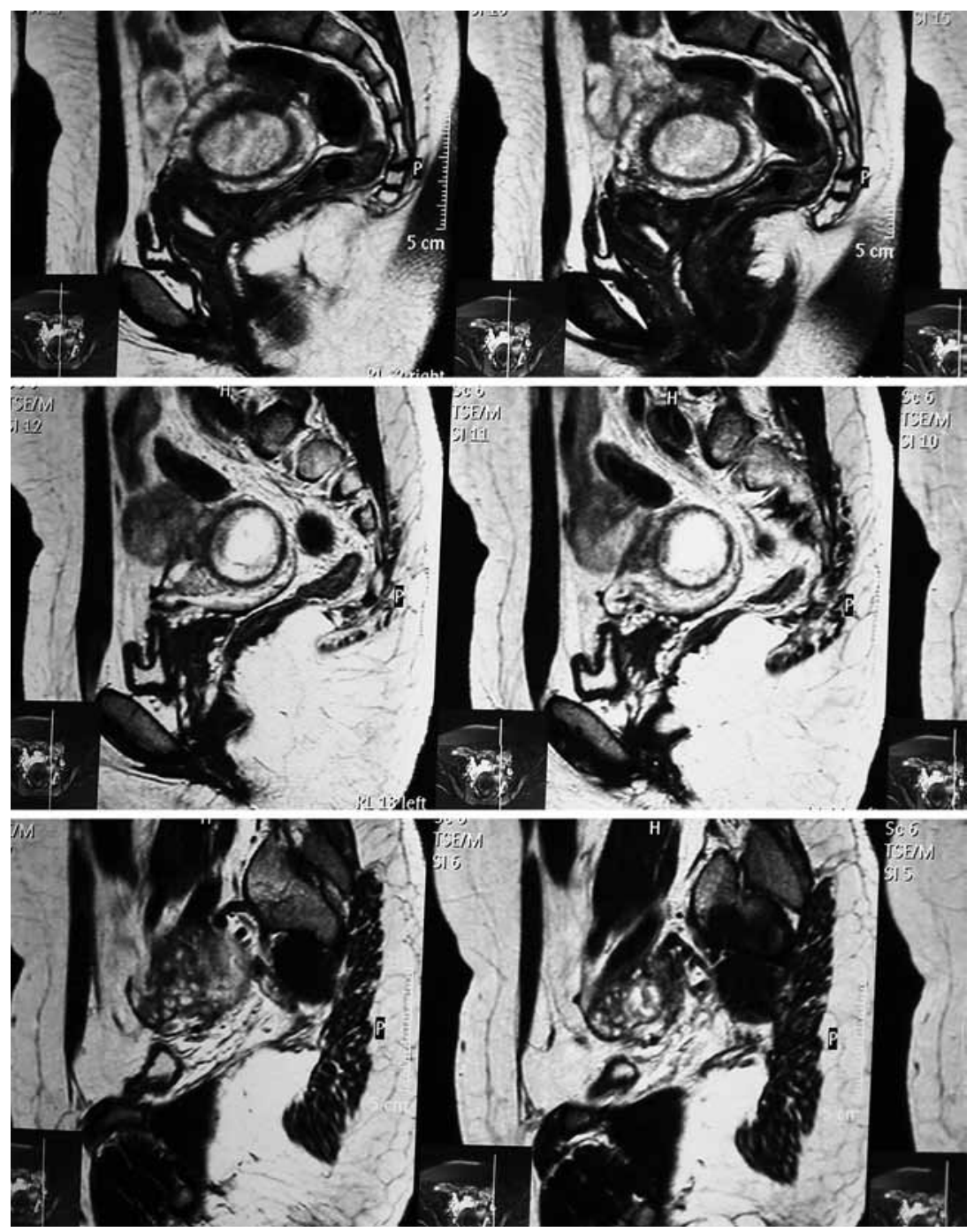

Fig. 1: T2-W coronal view showing pregnancy in left cornu

like abdominal pain, vaginal bleeding and hemorrhagic shock is present in about a quarter of patients. ${ }^{3}$ To prevent mortality and complications like hemorrhagic shock, early diagnosis is important which is facilitated by ultrasonography and serum hCG assays. Sonography is the usual method of diagnosis even in asymptomatic patients. The paucity of myometrium around gestational sac is diagnostic, while in angular pregnancy atleast $5 \mathrm{~mm}$ of myometrium is seen on all sides of gestational sac. ${ }^{8}$ Magnetic resonance imaging may be used particularly when it is important to distinguish between angular and interstitial pregnancy. The findings of sonography were confirmed by MRI in our patient. The traditional treatment of interstitial pregnancy has been laprotomy followed by cornual resection or hysterectomy. ${ }^{9}$ Successful laparoscopic resection of interstitial pregnancies has also been reported. ${ }^{10-13}$ Selective uterine artery embolization has also been successfully used as a mode of treatment. ${ }^{14}$ Conservative management with systemic methotrexate has also been tried but there is no consensus on the dose or number of methotrexate injections. Fisch et al reported successful use of local injection of methotrexate intra-amniotically along with systemic methotrexate in interstitial pregnancy. ${ }^{15} \mathrm{Al}$ Khan et al reported use of intravenous methotrexate in the successful management of interstitial pregnancy. ${ }^{16}$ Intra-amniotic etoposide injection use was reported by Cheng et al successfully in the management of cornual pregnancy. ${ }^{17}$ Although, it has been theorized that interstitial pregnancies are less susceptible to methotrexate due to increased blood supply. ${ }^{18}$ In a prospective-observational study in London, 17 out of 20 women with interstitial pregnancy were treated with single dose of intramuscular methotrexate, and second dose was given to six women who showed fall in hCG levels of less than $15 \%$ between day 4 and 7.4. The Royal College of Obstetricians and Gynecologists recommends that the women with tubal pregnancy who are most suitable for methotrexate therapy are those with a serum hCG levels of $<3000 \mathrm{IU} / 1$ and with minimal symptoms. ${ }^{19}$ Although nonsurgical treatment of cornual pregnancies have higher failure rates than treatment of ampullary pregnancies, we adopted conservative 
management as our patient was hemodynamically stable and nulliparous. Considering the very high hCG values at presentation 4 dose methotrexate regimen was given and with proper monitoring patient was successfully treated.

\section{CONCLUSION}

A nulliparous woman with history of recurrent abortions with interstitial pregnancy, consistent with 11 weeks of gestation was successfully treated with methotrexate injections despite high hCG levels, thus, avoiding surgery and preserving her reproductive function.

\section{REFERENCES}

1. Damario MA, Rock JA. Ectopic pregnancy. In: Rock JA, Jones HW III. Te Linde's Operative Gynecology. 9th ed. Philadelphia: Lipincott Williams \& Wilkins; 2003. p. 507-536.

2. Loret de Mola JR, Austin CM, Judge NE, Assel BG, Peskin B, Goldfarb JM. Cornual heterotopic pregnancy and cornual resection after in vitro fertilization/embryo transfer: a report of two cases. J Reprod Med 1995;40(8):606-610.

3. Soriano D, Vicus D, Maschiach R, Schiff E, Seidman D, Goldenberg M. Laproscopic treatment of cornual pregnancy: a series of 20 consecutive cases. J Reproductive Immunol 2008;90(3):839-843.

4. Jermy K, Thomas J, Doo A, Bourne T. The conservative treatment of interstitial pregnancy. BJOG 2004;111(11): 1283-1288.

5. Malinowski A, Bates SK. Semantics and pitfalls in the diagnosis of cornual/interstitial pregnancy. Fertility and Sterility 2006;86(6):1764.

6. Tulandi T, Al Jaroudi D. Interstitial pregnancy: results generated from the Society of Reproductive Surgeons Registry. Obstet Gynecol 2004;103:47-50.
7. Lau S, Tulandi T. Conservative medical and surgical management of interstitial ectopic pregnancy. Fertility and Sterility 1999;72:207-215.

8. Doubilet P, Benson CB. Atlas of ultrasound in obstetrics and gynecology. 9th ed. Philadelphia: Lipincott Williams \& Wilkins; 2003. ISBN: 7817-3633-1.

9. Faraj R, Steel M. Management of cornual (interstitial) pregnancy. Obstetr Gynaecol 2007;9:249-255.

10. Katz DL, Barrett JP, Sanfilippo JS, Badway DM. Combined hysteroscopy and laproscopy in the treatment of interstitial pregnancy. Am J Obstet Gynecol 2003;188:1113-1134.

11. Tulandi $T$, Vilos G, Gomel V. Laproscopic treatment of interstitial pregnancy. Obstet Gynecol 1995;85(3):465-467.

12. Grobman WA, Milad MP. Conservative management of a large cornual ectopic pregnancy. Human Reprod 1998;13(7): 2002-2004.

13. Moon HS, Choi YJ, Park YH, Kim SG. New simple endoscopic operations for interstitial pregnancies. Am J Obstet Gynecol 2000;182:114-121.

14. Dernelle P, Closset E. Management of interstitial pregnancy using selective uterine artery embolization. Obstet Gynecol 2006;107(2pt 1):427-428.

15. Fisch JD, Ortiz B, Taznke S, Chitkara U, Gindice L. Medical management of interstitial ectopic pregnancy: a case report and literature review. Hum Reprod 1998;13(7):1981-1986.

16. Al Khan A, Jones R, Fricchione D, Appuzio J. Intravenous methotrexate for the treatment of interstitial pregnancy. J Reprod Med 2004;49:121-122.

17. Cheng CL, Wang P, Chin C, Yang M, Hung J. Successful conservative treatment for advanced interstitial pregnancy. J Reprod Med 2002;47(5):424-426.

18. Barnhart K, Spandorfer S, Contifaris C. Medical treatment of interstitial pregnancy. A report of three unsuccessful cases. J Reprod Med 1997;42:521-524.

19. Royal College of Obstetricians and Gynaecologists. The management of tubal pregnancy. Green top guideline no. 21 May 2004; London: RCOG. 